\title{
Pengembangan Media Pembelajaran Matematika Berbasis Pendekatan Saintifik untuk Meningkatkan Kemampuan Komunikasi Matematis SMP Kelas VII
}

\author{
Rahmat Ridho Suradi ${ }^{1}$, Ali Asmar ${ }^{2}$, Yerizon ${ }^{2}$ \\ ${ }^{1}$ Mahasiswa Magister Pendidikan Matematika, FMIPA UniversitasNegeri Padang \\ ${ }^{2}$ Jurusan Matematika, FMIPA Universitas Negeri Padang \\ Email: ridhosuradi@gmail.com
}

\begin{abstract}
Learning results found in several schools are still low. This happens because students do not understand the real life math problems that surround students, so students are lack of creative thingking. This is because the learning methods used by teachers have not been implemented optimally. One of effort that can be made to overcome these problems is to use learning media based on interactive multimedia in the mathematic learning for 7 th grade of junior high school student who valid, practical and effective. This type of research is the development by using Plomp research design. During the initial survey phase, doing necessity analysis, curriculum analysis and conceptual analysis focused on issues related to learning mathematics. In the development phase or prototyping, the design of mathematics media learning based on a scientific approach to improve students' mathematical communication skills, then self-evaluation, one to one evaluation and small group evaluation. The assessment phase carried out a practicality test and a limited effectiveness test. Practicality data were obtained from teacher practicality questionnaires, student practicality questionnaires. Effectiveness data obtained from studentmresult learning after implementing learning with learning devices.The research results showed that the mathematics learning media with macromedia flash based on scientific was valid and practical. Valid because it has qualify the valid criteria in terms of construct and content. Practical because they are easy to use and understand, attractive, the allocated allocations are very efficient. Effectiveain terms of it's potential impact on students' mathematical communication skills.
\end{abstract}

Keywords: Development Media Learning, Scientific Approach, Mathematical Communication Skill.

Abstrak : Hasil belajar yang ditemui di beberapa sekolah cukup rendah. Hal tersebut terjadi karena siswa kurang paham terhadap masalah matematika yang berhubungan dengan kehidupan sehari-hari yang terdapat di sekitar sehingga siswa kurang kreatif dalam berpikir. Hal tersebut terjadi dikarenakan guru dalam penggunaan media pembelajaran belum terlaksana dengan optimal. Upaya yang dapat dilakukan untuk mengatasi permasalahan tersebut salah satunya adalah dengan mengunakan media pembelajaran berbasis multimedia interaktif pada pembelajaran matematika siswa kelas VII SMP yang valid, praktis dan efektif.Jenis penelitian ini yaitu pengembangan dengan menggunakan rancangan penelitian Plomp. Pada fase investigasi awal dilakukan analisis kebutuhan, analisis kurikulum, dan analisis konsep terkait permasalahan dalam pembelajaran matematika. Pada fase pembuatan atau pengembangan prototipe dilakukan perancangan media pembelajaran matematika berbasis pendekatan saintific untuk meningkatkan kemampuan komunikasi matematik siswa, kemudian dilakukan evaluasi sendiri, evaluasi satu-satu dan evaluasi kelompok kecil. Fase penilaian dilakukan uji praktikalitas dan ujiaefektivitas secara terbatas. Data praktikalitas diperoleh berdasarkan angket praktikalitas guru dan angket praktikalitas siswa. Data efektivitas diperoleh berdasarkan hasil belajar siswa setelah melaksanakan pembelajaran dengan perangkat pembelajaran. Hasil penelitian menunjukan bahwa media pembelajaran matematika dengan menggunakan macromedia flash berbasis saintifik sudah valid dan praktis. karena telah memenuhi kriteria valid dari segi konstruk dan isi maka media dinyatakan valid. Selanjutnya dikatakan praktis karena mudah dalam menggunakannya serta mudah untuk dipahami, menarik, alokasi waktunya sangat efisien. Efektif dari segi dampak potensialnya terhadap kemampuan komunikasi matematis siswa.

Kata kunci: PengembanganMedia Pembelajaran, Pendekatan Saintifik, Kemampuan Komunikasi Matematis. 


\section{PENDAHULUAN}

Matematika merupakan salah satu disiplin ilmu dan menjadi pendukung bagi keberadaan ilmu-ilmu lainnya (Muijs \& Reynold, 2011). Berdasarkan Permendikbud nomor 58 tahun 2014 tujuan pembelajaran matematika yaitu mengkomunikasikan penalaran, ide/gagasan, serta dapat menyusun bukti matematika menggunakan tabel, simbol, diagram, kalimat yang lengkap, dan media lainnya untuk menjelaskan keadaan/masalah. Maksudnya disini yaitu siswa mampu mengkomunikasikan permasalahan yang ditemui dalam pembelajaran matematika.

Komunikasi pada saat pembelajaran matematika dapat berlangsung antara siswa dengan guru, antara siswa dengan guru, dan antara siswa dengan siswa. Pada saat guru memberikan sebuah konsep kepada siswa ataupun siswa dilibatkan secara aktif dalam bermatematika, memikirkan ide-ide, berbicara, atau menulis dan memperhatikan siswa lain dalam diskusi, maka pada saat itu sedang berlangsung komunikasi matematika. Komunikasi matematika ini dapat berperan dengan baik dengan cara menciptakan suasana kondusif di dalam pembelajaran sehingga mengoptimalkan kemampuan siswa dalam komunikasi matematika.

Keberadaan komputer yang semakin meluas hingga sekolah dasar kurang dimanfaatkan oleh guru. Hal ini dikarenakan pemanfaatan komputer dalam proses pembelajaran terlalu menyita waktu yang banyak dalam persiapan dan pendesainan materi. Namun sesungguhnya penggunaan komputer dalam pembelajaran dapat mengefisiensikan waktu. Wena (2013:205) menyatakan bahwa penggunaan komputer memiliki keuntungan: 1) dapat mengakomodasi siswa yang lamban, 2) dapat merangsang siswa, dan 3) dapat menyesuaikan dengan tingkat kemampuan belajar siswa. Menurut Ilhan (2011) penggunaan komputer dalam pembelajaran, siswa dapat menemukanbanyak kesempatan untuk menyelidiki hubungan antara konsep-konsep matematika. Sesungguhnya penggunaan komputer pada proses pembelajaran dapat menarik perhatian, meningkatkan minat, serta meningkatkan prestasi belajar.

Salah satu permasalahan yang ditemui oleh guru matematika saat pembelajaran matematika di sekolah yaitu media pembelajaran yang guru gunakan ketika mengajar masih sangat terbatas, mengakibatkan guru mangalami kesulitan untuk menyampaikan materi yang membutuhkan visualisasi, sehingga siswa menjadi kesulitan saat memahami materi yang disampaikan oleh guru dan membuat hasil belajar kurang memuaskan. Hal ini disebabkan karena keterampilan guru dalam mengembangkan media belum cukup bagus. Durasi penyampaian materi dalam pembelajaran matematika yang relatif cukup singkat menjadi salah satu kendala dalam ketercapaian tujuan pembelajaran. Kendala keterbasan waktu belajar di kelas sebenarnya dapat disiasati dengan belajar dimana saja jika siswa memiliki alternatif dan motivasi media belajar mandiri.

Guru harus mampu kreatif untuk menciptakan suatu media interaktif yang mampu membuat siswa mudah untuk memahami materi supaya tujuan pembelajaran dapat tercapai. Oleh karena itu, agar permasalahan tersebut dapat teratasi maka sangat perlu untuk dikembangkannya suatu media pembelajaran interaktif. Adapun alasan yang 
melatar belakangi pentingnya pembuatan media ini yaitu menurut Wina (2014) bahwasanya seorang guru dituntut untuk mendesign pembelajaran dengan menggunakan berbagai jenis media dan sumber belajar yang cocok agar proses pembelajaran berlangsung secara efisien dan efektif. Ditambah lagi dengan berkembang pesatnya teknologi seperti komputer dan smartphone yang bisa digunakan sebagai media pembelajaran.

Multimedia pembelajaran juga dapat memberikan kebebasan bagi siswa dalam memilih dan menentukan materi yang diinginkan, karena siswa dapat mengulang materi yang belum dipahami. Menurut Aminah (2010) menyatakan bahwa pembelajaran dengan menggunakan multimedia lebih interaktif dan lebih baik dibandingkan dengan pembelajaran tradisional. Tidak hanya itu, multimedia pembelajaran juga dapat memberikan interaksi umpan balik yang sangat baik dari latihan dan soal-soal yang tersedia. Penggunaan multimedia dalam pembelajaran siswa lebih mandiri dalam mendapatkan dan mengembangkan ilmu pengetahuan yang dimiliki.

Menurut Mayer \& Moreno (2010) menyatakan bahwa multimedia yang terdiri atas gambar dan kata-kata berpotensi meningkatkan kapasitas pemrosesan informasi yang lebih tinggi dari diri siswa untuk dapat memahami meteri. Selanjutnya Chumaidi (2016) menyatakan bahwa dalam pembelajaran menggunakan multimedia terjadi situasi dimana gambar, animasi dan suara hadir sekaligus. Hal tersebut dapat mengakibatkan siswa untuk menyatakan suatu situasi, gambar, diagram, dan benda yang nyata ke dalam simbol, idea, bahasa dan model matematika.

Media pembelajaran sangat membantu guru untuk berkomunikasi dengan siswa dalam menjelaskan materi pelajaran baik secara online maupun offline. Melalui komunikasi, ide matematika dapat dimunculkan dari berbagai perspektif sehingga pola dan cara berfikir siswa dapat dipertajam serta meningkatkan pemahaman. Komunikasi matematis sangat penting, hal tersebut dikarenakan matematika tidak hanya membantu siswa sebagai alat untuk berfikir dalam mengembangkan pola, memecahkan masalah serta menarik suatu kesimpulan akan tetapi juga dapat sebagai alat untuk mengkomunikasikan gagasan, pikiran, dan ide secara jelas, singkat \& tepat.

Media pembelajaran interaktif yang dapat mengatasi permasalahan tersebut salah satunya adalah dengan penggunaan media pembelajaran interaktif menggunakan software Macromedia Flash. Menurut Putri (2019) menyatakan bahwa macromedia flash adalah software komputer yang bisa digunakan untuk mengembangkan media pembelajaran berbasis multimedia interaktif. Tools \& menu yang terdapat pada software tersebut mempunyai kemampuan untuk mendesign materi pembelajaran dengan langkah-langkah pembelajaran yang diinginkan, sehingga membuat siswa berinteraksi secara interaktif dalam kegiatan pembelajaran matematika.

Untuk mengatasi hal tersebut telah dilakukan penelitian pengembangan media pembelajaran matematika dengan menggunakan macromedia flash berbasis pendekatan saintifik untuk meningkatkan kemampuan komunikasi matematis peserta didik SMP kelas VII. Tujuan dari penelitian inia dalah untuk mendapaatkan media pembelajaran yang valid, praktis dan efektif. Perangkat ini diharapkan memberikan kemudahan bagi 
siswa untuk memahami materi dan meningkatkan kemampuan komunikasi matematis. Artikel ini membahas tentang "Bagaimanakah karakteristik dari media pembelajaran matematika berbasis pendekatan saintifik untuk meningkatkan kemampuan komunikasi matematis siswa kelas VII SMP yang valid, praktis, dan efektif?

\section{METODE}

Pengembangan pada penelitian ini menggunakan model plomp yaitu investigasi awal (preliminary research phase), tahapan pengembangan (pembuatan) prototipe (development or prototyping phase), dan tahapan penilaian (asssessment phase). (Plom \& Nieveen: 2013)

Tujuan dari Fase investigasi awal yaitu untuk mendefinisikan dengan jelas detil produk berupa perangkat pembelajaran yang akan dirancang. Kegiatan yang dilakukan pada tahap investigasi awal meliputi analisis masalah dan kebutuhan, analisis siswa, analisis kurikulum, dan analisis konsep. dan me-review literatur yang relevan untuk membuat konsep tentang karakteristik dan spesifikasi produk.

Menurut Nieveen dalam Plomp (2013) menyebutkan bahwa sejumlah kriteria umum untuk mendapatkan kualitas interverensi yang tinggi disebut dengan validasi (validity), praktikalitas (practicality), dan efektifitas (efectiveness). Evaluasi formatif terdapat pada seluruh fase dan siklus iterasi dalam penelitian pengembangan. Tessmer (dalam Plomp, 2013:36), mengungkapkan bahwa evaluasi formatif mempunyai beberapa lapisan seperti diilustrasikan pada gambar dibawah ini.

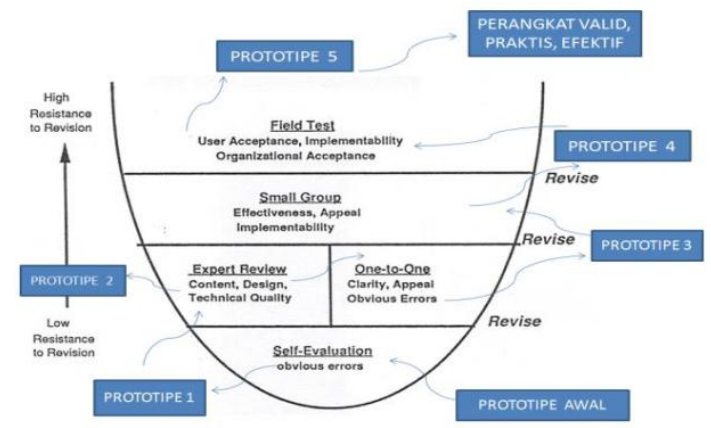

Gambar 1. Prosedur EvaluasiPengembangan Perangkat

Siswa SMPN 01 Sungai Geringging merupakan subjek uji coba pada penelitian untuk melihat tingkat praktikalitas dan efektivitas dari media interaktif yang telah dihasilkan. Jenis data yang diperoleh dari penelitian yang akan dilakukan yaitu data kualitatif yang didapatkan dari hasil wawancara, diskusi, dan observasi peneliti dengan guru dan siswa sementara itu data kuantitatif diperoleh dari lembaran observasi, dan angket. Lembar instrumen validitas, praktikalitas, dan efektivitas merupakan instrumen yang digunakan pada saat mengumpulkan data.

\section{HASIL DAN PEMBAHASAN}

Tahapan yang dilakukan dalam proses $\&$ hasil pengembangan media interaktif yang valid, praktis serta efektif yaitu preliminary, prototyping dan assesment. Pada tahap preliminary dilakukan analisis konsep, kebutuhan, siswa dan kurikulum. Berdasarkan pada hasil analisis di tahap preliminary maka dirancang suatu media interaktif berbasis 
pendekatan saintifik. Selanjutnya media interaktif pembelajaran berbasis pendekatan saintifik dievaluasi sendiri \& divalidasi oleh para ahli.

Setelah dihasilkan media pembelajaran interaktif berbasis pendekatan saintifik yang valid, untuk melihat kepraktisan media interaktif pembelajaran dilakukan evaluasi perorangan dan evaluasi kelompok kecil. Efektivitas ditinjau dari kemampuan hasil belajar matematika siswa berdasarkan hasil tes akhir siswa kelas VII.2. Dikarenakan keterbatasan peneliti pada penelitian ini maka prosedur penelitian yang dijalankan hanya sampai pada tahap uji evaluasi kelompok kecil dan revisi produk.

Hasil analisis kebutuhan diperoleh kesimpulan bahwa guru dan siswa membutuhkan media interaktif dalam pembelajaran matematika agar terjadi proses pembelajaran yang membuat siswa untuk dapat aktif dan efektif .

Selanjutnya berdasarkan analisis terhadap kurikulum dipilih pengembangan media interaktif pembelajaran untuk materi perbandingan pada kelas VII. Berdasarkan KI dan KD pada materi perbandingan maka mendukung dalam pengembangan produk yang bisa menjadikan siswa lebih aktif dalam belajar. Analisis konsep dilakukan dengan mengidentifikasi konsep-konsep utama yang akan dipelajari oleh siswa dan menyusunnya secara sistematis berdasarkan urutan penyajiannya. Materi yang dikembangkan yaitu perbandingan.

Hasil analisis angket menyatakan bahwa media pembelajaran interaktif yang diinginkan oleh siswa yaitu tampilannya cukup menarik, didominasi warna biru dan hijau, dan dilengkapi gambar yang menarik. Berdasarkan karakter yang penulis temui dari hasil analisis maka peneliti sangat perlu mengembangkan suatu media interaktif agar dapat memfasilitasi karakter yang dimiliki siswa menuju arah yang lebih positif. Maka dibuatlah sebuah media pembelajaran interaktif.

Kategori hasil validasi media pembelajaran matematika yaitu sangat valid dengan nilai pada masing-masing aspek yang dinilai. Berdasarkan data, dapat disimpulkan media pembelajaran matematika berbasis pendekatan saintifik berada pada kategori sangat valid.

Evaluasi one to one dilakukan dengan meminta 3 siswa yang memiliki kemampuan yang berbeda untuk mencoba menggunakan media dan memberikan komentar terhadap media yang dirancang. Setelah melakukan one to one evaluation, peneliti melakukan perbaikan media interaktif pembelajaran berbasis pendekatan saintifik untuk mendapatkan media interaktif pembelajaran yang lebih baik lagi.

Setelah dilakukan revisi berdasarkan hasil evaluasi perorangan, selanjutnya media interaktif pembelajaran diujicobakan praktikalitasnya pada kelompok kecil (small group) dengan mempraktekkan media interaktif pembelajaran yang telah dirancang pada siswa yang berjumlah 6 orang dari kemampuan tinggi, sedang dan rendah dan dibagi menjadi 2 kelompok dengan kemampuan yang berbeda-beda. Media pembelajaran matematika yang dibuat dengan aplikasi macromedia flash.

Angket praktikalitas diberikan pada guru setelah pembelajaran dilaksanakan. Nilai praktikalitas yang diperoleh dengan menggunakan angket respon guru yaitu 89,58\%. Berdasarkan kriteria tersebut, maka dapat disimpulkan bahwa praktikalitas media 
interaktif pembelajaran berbasis pendekatan saintifik yaitu sangat praktis. Berdasarkan angket yang diisi oleh guru terlihat bahwa media mudah untuk digunakan, dipahami, menarik dan memotivasi siswa dalam belajar matematika.

Angket praktikalitas diberikan kepada siswa sesudah mengikuti pembelajaran menggunakan media berbasis pendekatan saintifik. Pada Tabel 4 berikut ini dapat dilihat hasil uji praktikalitas menurut respon siswa.

Tabel 4. Hasil Uji Praktikalitas Menurut ResponSiswa

\begin{tabular}{lll}
\hline Aspek yang Dinilai & Persentase (\%) & Kategori \\
\hline Aspek Penyajian & 87,24 & Sangat Praktis \\
Aspek Kemudahan Penggunaan & 86,33 & Sangat Praktis \\
Aspek Waktu & 86,72 & Sangat Praktis \\
Aspek Keterbacaan & 87,14 & Sangat Praktis \\
\hline Rerata Keseluruhan & 87,14 & Sangat Praktis \\
\hline
\end{tabular}

Dari ketiga aspek praktikalitas media berbasis pendekatan saintifik menurut respon siswa diperoleh rerata tingkat kepraktisan adalah 87,14\%. Sehingga bisa disimpulkan bahwa media berbasis pendekatan saintifik praktis berdasarkan respon siswa.

Menurut Arikunto (2012) validitas adalah suatu ukuran yang menyatakan tingkat keandalan (kesahihan) suatu alat ukur, validitas yang di diukur pada penelitian ini yaitu validitas konstruk \& validitas isi. Tujuan dari validitas isi untuk mengukur kesesuaian materi pelajaran yang diajarkan. Selanjutnya menurut Arikunto (2012) validitas konstruk yaitu kesesuaian susunan media interaktif dengan pendekatan pembelajaran berbasis pendekatan saintifik.

Kriteria kevalidan sebuah produk yang dikembangkan yaitu dari segi isi dan konstruk. Pada tahap validasi media ini kriteria tersebut dikembangkan kedalam aspek didaktik, isi, bahasa, dan penyajian. Sesudah dilakukannya validasi diperoleh hasil validasi media dalam segi didaktik adalah 3,33 yang dirumuskan sudah tergolong sangat valid. Berdasarkan hasil validasi aspek didaktik media, dapat dibuat kesimpulkan bahwa media sudah memuat permasalahan translasi dan masalah aplikasi, melibatkan siswa secara aktif memecahkan masalah matematika, memotivasi siswa untuk bertanya, memotivasi siswa mempelajari lebih jauh konsep matematika.

Aspek yang dinilai selanjutnya yaitu aspek isi. Berdasarkan validasi aspek isi, diperoleh nilai kevalidan 3,14 yang sudah tergolong valid. Isi yang terdapat pada media sangat jelas. Sehingga bisa disimpulkan bahwa media tersebut telah memenuhi prinsip ketepatan dan kedalaman materi. Media sudah memuat materi yang sesuai dengan KI, $\mathrm{KD}$, dan indikator yang sesuai dengan kemampuan matematis siswa.

Bahasa dan aspek keterbacaan media sudah jelas, kalimat yang digunakan di dalam media sesuai dengan kaidah Bahasa Indonesia, kalimat sudah komunikatif, informasi jelas, menggunakan ukuran huruf dan bentuk sesuai karakteristik siswa, dan menggunakan bahasa yang dapat memotivasi siswa untuk melakukan kegiatan pembelajaran. Ini sesuai dengan nilai kevalidan yang diperoleh 3,28 yang dikategorikan sangat valid. Aspek tampilan yang dirumuskan juga sudah tergolong sangat valid dan 
tampilan dalam media sudah tergolong jelas dan menarik dengan nilai kevalidan yang diperoleh 3,00. Ini berarti tampilan pada media sudah memenuhi aspek yang diharapkan.

Suatu media interaktif yang baik haruslah praktis. Adapun Kriteria yang digunakan dalam menilai praktikalitas pada pengembangan media interaktif ini yaitu berdasarkan keterlaksanaan pembelajaran dengan menggunakan media interaktif pembelajaran matematika berbasis pendekatan saintifik, selanjutnya berdasarkan mudahnya media interaktif tersebut digunakan oleh guru dan dipahami siswa, dan cukupnya waktu yang disediakan dalam melaksanakan media interaktif tersebut. Hal ini sejalan dengan pendapat (Putrawan: 2014) menyatakan bahwa media interaktif pembelajaran matematika yang dikembangkan dilihat dari respon guru \& siswa tergolong praktis.

Dalam menilai kepraktisan pada media interaktif ini, melalui observasi pada pelaksanaan pembelajaran dan angket praktikalitas yang diisi oleh guru dan siswa sehingga diperolehlah data. Proses pembelajaran dapat mendorong siswa dalam mengeluarkan pendapat, bertanya, menjawab soal dan antara siswa terjadi interaksi untuk pelaksanaan pembelajaran dengan menggunakan media interaktif pembelajaran berbasis pendekatan saintifik. Sehingga mampu merangsang siswa dengan baik untuk meningkatkan motivasi siswa, mengembangkan kreativitas, dan mandiri waktu menyelesaikan soal-soal.

Efektivitas media interaktif pembelajaran matematika berbasis pendekatan saintifik dilihat dari hasil belajar siswa. Hasil belajar didapatkan melalui tes akhir sesudah materi perbandingan selesai diajarkan. Berdasarkan hasil tes akhir siswa kelas VII SMPN 01 Sungai Geringging diperoleh nilai rerata 81 dan berada di atas KKM.

\section{SIMPULAN \& SARAN}

Kesimpulan penelitian ini media pembelajaran matematika dengan pendekatan saintifik yang dikembangkan sudah valid, dan praktis berdasarkan evaluasi one to one dan uji kelompok kecil. Media ini mampu mendorong terjadinya peningkatan kemampuan komunikasi matematis siswa untuk setiap indikatornya. Media dapat digunakan dalam pembelajaran matematika SMP kelas VII semester II.

Adapun saran bagi peneliti lain diharapkan mengembangkan lebih lanjut perangkat pembelajaran matematika dengan inovasi dan kreasi baru dengan harapan proses dan hasil belajar matematika yang lebih baik.

\section{DAFTAR PUSTAKA}

Aminah, A. Tan, S.Y. Loh, Y.F. Yap, H.Y. Khoh, W.H. 2010. Incorporating Multimedia as a tool into mathematic education : a case study on diploma students in multimedia university. international journal mathematic education research ( http://www.sciencedirect.com/science/ article/pii/S1877042810021877).

Adi Putrawan,Agus .2014. Pengembangan Perangkat Media Pembelajaran Matematika dengan Pendekatan Saintifik Berbantuan Geogebra untuk Meningkatkan Keterampilan Komunikasi Matematik dan Aktivitas Belajar Matematika Siswa Kelas VIII SMP. E-jurnal Program Pascasarjana. Universitas Ganesa.

Arikunto, Suharsimi. 2012. Dasar-dasar evaluasi pendidikan. Jakarta : Bumi Aksara. 
Chumaidi dan Ahmad, C. 2016. Pengembangan Multimedia Interaktif Mata Pelajaran Biologi Kelas X Semester II di SMA Wahid Hasyim Lamongan. Vol.1. No.3. Hal 507-520.

Ilhan, K. 2011. experiences of student mathematic teachers in computer based mathematics learning envirnment. international journal for mathematic teaching and learning. (http:/www.cimt.plymouth.ac.uk/journal/karatas.pdf).

Mayer, R.E \& Moreno, R. 2010. Cognitive Load Theory : Techniques that Reduce Extraneous Cognitve Load and Manage Intrinsic Cognitive Load during Multimedia Learning. Cambridge ; Tecnique that Increase Generative Processing in Multimedia Learning : Open Question for Cognitive Load Research. Cambridge : Cambridge University Press.

Muijs dan Reynolds. (2011). Effectiv teaching: Aplikasi dan Teori. Jogjakarta: Pustaka Pelajar.

Plomp, T dan N. Nieven. 2013. Educational Design Research. Enshede; Netherland Institute for Curiculum Development.

Putri, J Hidayah. 2019. Developing mathematics learning media based on macromedia flash by using problem based learning to improve students mathematical spatial ability. American journal of educational researc, Vol. 7, No. 10, 708-712.

Sanjaya, Wina. 2014. Strategi Pembelajaran Berorentasi Standar Proses pendidikan. Jakarta: Kencana Prenada media. Cet. XI

Wena, M., 2013. Strategi Pembelajaran Inovatif Kontenporer. Jakarta; PT Bumi Aksara 